\title{
What are universities for?
}

\author{
Geoffrey BOULTON ${ }^{1 *} \&$ Colin LUCAS ${ }^{2}$ \\ ${ }^{1}$ The University of Edinburgh, Edinburgh EH9 3JL, UK; \\ ${ }^{2}$ University of Oxford, Oxford OX1 3DW, UK
}

Received March 9, 2011; accepted May 31, 2011

\begin{abstract}
Governments worldwide rightly regard universities as fundamental to the achievement of many national priorities. But it is the paper's contention that many misunderstand their true benefit to society. Investments in universities are increasingly based on the belief that the science labs in particular of research-intensive universities can be the source of a continuous stream of people and ideas that will spawn innovative and fast growing companies to form the nexus of the knowledge-based economy. This belief is a source of misconceived policies that offer only ultimate disillusion. It is the totality of the university enterprise that is important, as the only place where that totality of ourselves and our world is brought together, and which makes it the strongest provider of the rational explanation and meaning that societies need. In research, universities create new possibilities; in teaching, they shape new people. Its graduates learn to seek the true meaning of things: to distinguish between the true and the merely seemingly true, to verify for themselves what is stable in that very unstable compound that often passes for knowledge. It is the complex, interacting whole of the university that is the source of the separate economic, social, cultural and utilitarian benefits valued by society. It needs to be understood, valued and managed as a whole. These perceptions are a direct challenge to not only to governments but to university administrators who have been either cowed or seduced into the slipshod thinking that is leading to demands that universities cannot satisfy, whilst obscuring their most important contributions. The challenge to both is to permit autonomy without oppressive accountability, and to give staff and students the freedom to think, speculate and research. These are the very conditions of the personal and collective creativity that are the sources of a university's deepest benefits to its society.
\end{abstract}

universities, higher education, research, society, economy, culture, academic freedom

Citation: Boulton G, Lucas C. What are universities for? Chinese Sci Bull, 2011, 56: 2506-2517, doi: 10.1007/s11434-011-4608-7

\section{The idea of the university}

"A University is a place ... whither students come from every quarter for every kind of knowledge; ... a place for the communication and circulation of thought, by means of personal intercourse. ... It is the place to which a thousand schools make contributions; in which the intellect may safely range and speculate. It is a place where inquiry is pushed forward, ... discoveries verified and perfected, and .. error exposed, by the collision of mind with mind, and knowledge with knowledge. ... Mutual education, in a large sense of the word, is one of the great and incessant

*Corresponding author (email: geoffrey.boulton@ed.ac.uk) occupations of human society. .. One generation forms another.... We must consult the living man and listen to his living voice, .. by familiar intercourse to adjust together the claims and relations of their respective subjects of investigation. Thus is created a pure and clear atmosphere of thought, which the student also breathes." So wrote John Henry Newman in The Idea of a University in 1852. [1]

Some 40 years earlier, in 1810, Wilhelm von Humboldt wrote a memorandum [2] that led to the creation of the University of Berlin. He envisaged a university based on three principles: unity of research and teaching, freedom of teaching and academic self-governance. The first was critical both of research divorced from teaching, undertaken by private scholars or in separate research institutes, without the stimulation of sharing those investigations with young 
minds, and of higher education divorced from original enquiry. The second, Freiheit der Lehre und des Lernens, was that professors should be free to teach in accordance with their studiously and rationally based convictions. The third principle, of academic self-government, only implicit in Humboldt's memo but increasingly apparent as an integral component of his vision, was meant to protect academic work from the distortions of government control.

The perceptions of Newman and Humboldt have dominated western thinking about the functions of universities. They are represented to different extents and in different ways in the objectives and structures of the comprehensive, research universities of Europe. They are sometimes considered to be antithetical, implying that the ethos of specialised research is in tension with the liberal education of an informed and critical citizen. That may simply be a reflection of the openness to contradiction that is part of the genius of the university. For our part, we see them as complementary and the western comprehensive university to be in many ways the fusion of the two. Thus, Newman's "discoveries verified and perfected and error exposed by the collision of mind with mind, and knowledge with knowledge" is a powerful basis for Humboldt's search for new knowledge through research. Equally, to consult "the living man and listen to his living voice" emphasises the virtue of tuition by researchers who, with first-hand rather than secondhand knowledge, are best able to penetrate with their students the complex tangle in which true knowledge often lies.

\section{The success of the western university model}

The "western" university based on Newman's and Humboldt's principles has been remarkably successful. It has provided an almost universal model for higher education. The highly interactive social setting and operational freedom of such universities has stimulated a creativity that has made them one of the great entrepreneurial centres of the modern world. They are one of the fundamental agents that have made that world possible. Their capacities have been such that not only has their historical commitment to education and scholarship flourished and deepened, but they have absorbed in the last 40 years a massive increase in student numbers. They have been widely emulated, and arguably are sources of radical thought and social progress in societies where they have been introduced. In many countries they have also become the principal locations for the national research base, and have led the way in developing the cross-disciplinary concepts that are increasingly vital if we are to address many of the complex challenges to national and global societies.

Indeed, this flexibility and adaptability have become the hallmarks of universities. They are testimony both to a dynamic process of engagement in the pursuit and explanation of knowledge and to a sensitivity to the needs of the contemporary world and to the problems that preoccupy it. Universities operate on a complex set of mutually sustaining fronts - they research into the most theoretical and intractable uncertainties of knowledge and yet also seek the practical application of discovery; they test, reinvigorate and carry forward the inherited knowledge of earlier generations; they seek to establish sound principles of reasoning and action which they teach to generations of students. Thus, universities operate on both the short and the long horizon. On the one hand, they train students to go out into the world with both general and specific skills necessary to the wellbeing of society; they work with contemporary problems and they render appropriate the discoveries and understanding that they generate. On the other hand, they forage in realms of abstraction and domains of enquiry that may not appear immediately relevant to others, but have the proven potential to yield great future benefit.

If we may borrow a phrase from the founders of the American Philosophical Society ${ }^{1)}$, universities are concerned to create and transmit "useful knowledge". Inescapably, the definition of useful knowledge is relative: it is partly what is practically useful; it is partly what serves the broadest purpose of rendering the human condition and the world we live in coherent to us; and it is also partly the preparation of what we do not yet know to be useful knowledge.

There is no doubt that universities have been remarkably successful in this, as is shown by the degree to which contemporary governments and societies pay them so much attention. Nonetheless, as we shall argue, the conditions of that success are quite specific. Indeed, whatever attention must necessarily be given to corporate effectiveness, universities are not enterprises with a defined product with standardized processes required for its cost-effective production. Universities generate a wide diversity of outputs. In research, they create new possibilities; in teaching, they shape new people. The two interact powerfully to generate emergent capacities that are adapted to the needs of the times, embodying and creating the potential for progress through the ideas and the people that will both respond to and shape an as yet unknown future.

It is important to remember that whatever policy-driven demands are placed on universities and whatever the desire to mandate particular outcomes, the space of university endeavour is essentially one where discoveries cannot be determined in advance and where the consequences of the encounter between minds, between a mind, a problem and evidence, and between the minds of successive different generations are profoundly and marvelously unpredictable.

1) The American Philosophical Society was set up in 1743 as the "American Philosophical Society held at Philadelphia for the promotion of useful knowledge". 
They are the very conditions of creativity.

\section{A changing world}

These enduring elements of success explain why, in the world of globalisation, universities are now regarded as crucial national assets. Governments worldwide see them as vital sources of new knowledge and innovative thinking, as providers of skilled personnel and credible credentials, as contributors to innovation, as attractors of international talent and business investment into a region, as agents of social justice and mobility, and as contributors to social and cultural vitality.

It is not surprising therefore that universities have moved from the periphery to the centre of government agendas. Governments around the world have invested heavily in universities and made demands upon them about objectives and even the processes used to attain them. The European Union serves as an example: it has promoted a "modernisation agenda" for university reform "as a core condition for the success of the broader Lisbon Strategy [3] to make the European Union "the most dynamic and competitive knowledge-based economy in the world" [4]. The European Commission has defined the role of universities as to exploit the so-called "knowledge triangle of research, education and innovation"[5], and has set about creating its own university, the European Institute of Innovation and Technology, to demonstrate how these objectives should be addressed.

Thus, over the last decade or so there has been firmly established among governments around the world the view that high quality, internationally competitive research and higher education, mostly contained within universities, are prerequisites for long-term success in globalised knowledge economies. These are perceptions that drive the policy debate in Europe and elsewhere about how university systems can affordably embrace both research universities capable of vying with the world's best, and provide higher education for a large proportion of the rising generation.

This policy preoccupation with the immediate challenges of a world in transition has led to a growing tendency to see universities as sources of highly specific benefits. This means in particular that they are (or should be) sources of marketable commodities for their customers, be they students, business or the state. There are injunctions to redesign/repackage and sell their products in response to shifting consumer priorities and to the immediate gratification of the marketplace.

Indeed, what is striking is that the realisation of the importance of universities in the context of globalization has brought governments of most of the major economies (other than the USA where other mechanisms operate ${ }^{2)}$ ) to seek to regulate and stimulate universities in order to make them instruments of social and economic public policy. Broadly speaking, public policy sees universities as vectors of the contemporary skilling of an increasing segment of the population and as providers of innovation that can be translated into advantage in a fast changing global economic environment. This involves the use of regulation and incentives (especially financial) to obtain forms of behaviour in universities that provide outcomes defined as desirable within this short-term frame of reference.

Public policy implies the engagement of universities in the contemporary concerns and objectives of their societies. We recognise that as both necessary and welcome. Public policy acknowledges the potential for the creativity of universities to benefit the economy. We recognise the validity of that premise. However, the contention of this paper is that such public policy needs to be moderated by a better understanding of the broad function of universities. We believe that the general attitudes that underlie such government policies are based on some serious misunderstandings. It is crucial that the true role of universities in modern societies and the relationships between means and ends are understood before mechanisms to promote change are put in place. Indeed, there is a danger that the current approach to universities is undermining the very processes that are the source of those benefits so cherished by government. It may staunch the universities' capacities to look beyond today's concerns in order to prepare the thoughts and the ideas that the future will need. Ultimately, they would be left as universities only in name.

\section{The new discourse: The primacy of direct economic benefit}

Increasingly, discussions of the organisation of research and indeed of the university system across Europe have become dominated by analyses of the ways in which they can best fulfil an immediate economic function [6]. But we should pause to consider whether both the end and the means to achieve it have been correctly identified.

The statements of government ministers, officials, funding agencies and research councils have in the last decade or so generally developed the following themes:

(1) that the function of universities is to provide direct in-out benefits for society's economic prosperity;

2) Duderstadt, J. J. "In the U.S., focused efforts by federal or state governments to utilize higher education to address particular near term priorities are less influential. While the cacophony of demands from the highly diverse stakeholders attempting to influence American higher education can be a headache for university leaders and governing boards, there is a moderating effect on the dominance of any particular agenda from the diversity of funding sources. Furthermore, the intensely competitive higher education marketplace in the U.S. in which faculty, students, and resources move easily from one institution to another has a self-correcting effect. If some institutions lose their way and become too focused on an agenda too far removed from their core academic competence, they will quickly lose faculty, students, and eventually reputation". Personal communication. April 2008. 
(2) that there is a direct relationship between university applied research and economic prosperity through the medium of scientific and technical innovation spreading into the economy;

(3) that there is a high correlation between prosperity, social contentment and university research in science and technology;

(4) and, by implication, that universities have a primary duty to engage in this socially useful activity in exchange for taxpayers' support, and that research should only be supported if it is in the immediate national interest.

The Chief Scientist of Australia recently epitomized such a view in his essay The Chance to Change [7] where he wrote of "the potential of universities to play a central role as dynamos of growth in the innovation process and be huge generators of wealth creation".

One direct consequence of these perceptions has been the enormously increased investment in university science research by many governments in recent decades. From the point of view of universities, this investment has indeed allowed a great upsurge in both the volume and the quality of science research. It is important for us to recognise here the substantial progress that has occurred in this domain. Moreover, in many universities there have been determined and effective developments in the application of new technologies derived from science research. There can be no doubt that large state investment has triggered institutional and individual creativity and the pursuit of more ambitious objectives.

Nonetheless, we argue that these outcomes are the byproducts of a policy constructed on flawed premises. Many governments have adopted a simplistic reductionism in their perception of the connection between universities and globalisation. Globalisation is certainly the child of the breathtaking scientific and technological advances that have created the developments in communication whose rapidity and universality have astonished the vast majority of people who do not understand the technology. Whether globalization is the creation of this technology or simply another version of the globalising tendency of nineteenth-century imperialisms hardly matters. What policy makers have seen is the power of technological innovation and the threat of world economic reordering that it poses. They have made a cursory connection between technology and science and then between science and the obvious place where public money is spent on it-universities. It is on this basis that policies of investing in university science with a particularly public benefit in view have emerged.

To our minds, all this has a curiously contradictory character of a post-Cold War revision of the significance of universities coupled with a dose of nationalism. Universitiesand more especially research-led universities-flourished in the Cold War as both sides sought both technological superiority and the demonstration that their values produced happier and more creative societies. After a period of growing indifference to universities as European communism failed in the 1980s, globalisation produced a new need for technological superiority and for the evidence of happier and more creative societies. The difference is that globalisation has produced anxiety about the performance of national economies (as distinct from international ideological systems) and happiness or quality of life is now classified by governments as essentially the product of economic success.

Indeed, it is a striking illustration of this point that the metaphor of global competition that reflects business rivalries in liberalised markets has inspired the rhetoric of crisis that colours many appraisals of the performance of Europe's universities. As league table follows league table, they are pored over obsessively for signs of progress or decline.

\section{The search for function and purpose}

Of course, one can see why universities and agencies that connect with them have moulded themselves to this vision of socially and economically relevant national objectives. On the one hand, the high level of funding for university science research is irresistible. This is not a base motive in the way that some highminded colleagues would have us believe. Universities need money, as do scientists in pursuit of ever more challenging research objectives and ever more expensive means to pursue them. No university operates well in indigence. On the other hand, universities are, and have always been, products of their society, whatever the persistence of an academic discourse of intellectual virginity. Universities are socially responsible and seek to improve the common good. Their perceptions and priorities change as those of their society change around them. Universities reconcile a transcendent mission of establishing understanding of the true nature of things with a social mission of relevance to their ambient population. This is not an easy task. What is attractive about current public policy for universities is that it does appeal to universities' desire for relevance in their mission.

Nonetheless, the contention of this paper is that the current emphasis of public policy about universities in Europe and elsewhere is far from capturing the essential reality of their function in society. Research universities in particular must be wary of simply accepting the premises of that policy as a whole truth. They must have a clear sense of their own about what they stand for and what their purpose is. They should not be rushed by a combination of inducements, urgency and regulation into accepting an identity proffered them from their ambient world, but they must engage with it to define a commonly accepted purpose. Even accepting the European Commission's knowledge triangle of educationresearch-innovation, universities need to provide their own answers to the questions: What sort of education? What sort of research? And how do universities contribute to innovation, previously believed to be the exclusive domain 
of private industry?

The phrase "useful knowledge" tends to imply the immediately applicable. But today's preoccupations are inevitably myopic, often ephemeral, giving little thought for tomorrow. The ideas, thoughts and technologies that tomorrow will need or that will forge tomorrow, are hid from us, and foresight exercises have had a lamentable record of success in attempting to predict them. Just as the breathtaking pace of scientific, technological and societal innovation has changed and is changing the way we live, in an unpredictable way, so will it in the future. The universities in their creative, free-thinking mode are a vital resource for that future and an insurance against it. The policies being increasingly pressed upon them implicitly assume a knowable future or a static societal or economic frame. As Drew Faust has said, in her inaugural address as President of Harvard [8]: "A university is not about results in the next quarter; it is not even about who a student has become by graduation. It is about learning that moulds a lifetime; learning that transmits the heritage of millennia; learning that shapes the future".

A university that moulds itself only to present demands is one that is not listening to its historians. History is at its most illuminating when written with the full consciousness of what people wrongly expected to happen. Even in the domain of technology, future developments only a few years away have been shrouded from contemporary eyes. Many, possibly most, have arisen unexpectedly from research with other objectives, and assessments of technological potential have invariably missed the mark. For example, Roosevelt's 1937 Commission to advise on the most likely innovations of the succeeding 30 years not only identified many unrealised technologies, but missed nuclear energy, lasers, computers, xerox, jet engines, radar, sonar, antibiotics, pharmaceuticals, the genetic code and many more. Thirty years ago, scientists who studied climate change were regarded as harmless but irrelevant. But the serendipitous investment in their works revealed processes that we now recognise as threatening the future of human society, and the successors to those scientists are playing a crucial role in assessing how we need to adapt. Francis Fukuyama's 1992 [9] claim of "The End of History" was soon falsified as, within a decade, history reinvented itself, gearing into fast-forward mode with unanticipated transformations in economic practice, in social and religious experience and political relationships.

Notwithstanding these lessons from the recent past, much current thinking about universities implies a predominant concern that they should gear themselves only to immediate demands. We argue that in research, in teaching and in learning it is not only important that universities address and train for current needs, but equally important that they develop the thinking and the mental and conceptual skills and habits that equip their graduates to adapt to change and even steer it if circumstances permit. Uncertainty about future relevance in the spectrum of research or of curricula is such that a Darwinian adaptive model is the most appropriate; where both range across the whole landscape of human understanding and experience, embodied not only in the natural sciences and technology but also in the arts, humanities and social sciences. The key to retaining the flexibility to exploit the unexpected lies in a fundamental understanding of the nature of phenomena. Such understanding continuously resynthesis specific knowledge in the form of general understanding that is broadly applicable, such that a complex narrative in one generation can be replaced by a simpler one in succeeding generations. Basic research that compresses and generalises understanding in this way invigorates teaching that probes the limits of understanding. Together, they are the fuel for the university engine. Such generic understanding also represents a fundamental "transferable skill" which can be applied to a much wider range of circumstances and phenomena than any catalogue of specific knowledge. It is a vital investment in the future.

\section{The university and "useful knowledge"}

We concur with the view that universities' fundamental contribution to society lies in creating and passing on "useful knowledge", and engaging with society in its application, but argue that the definition of utility is often too narrowly drawn. As is evident from the argument so far, we do not concur with the increasing assumption that useful knowledge is only that immediate knowledge which forms the basis for the technologies and skills believed to be crucial for economic success. Useful knowledge, and the skills that go with it, are derivative from a deeper capability that is insufficiently credited by government, and often relinquished for shallower perceptions of utility by the very academics who should most cherish it. It is a capability deeply embedded in the fundamental role that universities have in creating new knowledge and transmitting it to successive generations together with the knowledge which has been accumulated by predecessors and which in each generation is subjected to renewed tests of verification.

We argue that in practice, many of the qualities that governments prize in universities are by-products of deeper functions of the university. If those functions are undermined, the rest will also fail. The ideas and capacities that the future will need are a singularly important part of universities' work. Benefits are reaped long after the seeds are sown-one can justifiably say that there are two sorts of science: applied and not yet applied, and that the same is true of the whole domain of knowledge. Current policy preoccupations with the shortterm are fundamentally at odds with the sustainable effect which governments must hope for from universities over the longer term. Indeed, some governments increasingly place their emphasis exclusively on studies with near-term economic impact. 
Let us therefore examine how university contributions to society are achieved through their historic roles in education and research, and how they should best respond to current priorities for outreach, in contributing to innovation, and in public and international engagement. They are by no means all the roles that universities do or could play, but are the major parts of their current effort and the focus of current debate.

\subsection{Education}

There is, or should be, in university education, a concern not only with what is learned, but also with how it is learned. Too much pedagogy is concerned solely with the transfer of information. Even an education directed towards immediate vocational ends is less than it could be, and graduates are left with less potential than they might have, if it fails to engage the student in grappling with uncertainty, with deep underlying issues and with context. Generation by generation universities serve to make students think. They do so by feeding and training their instinct to understand and seek meaning. It is a process whereby young people, and those of more mature years who increasingly join them as students, are taught to question interpretations that are given to them, to reduce the chaos of information to the order of an analytical argument. They are taught to seek out what is relevant to the resolution of a problem; they learn progressively to identify problems for themselves and to resolve them by rational argument supported by evidence; and they learn not to be dismayed by complexity but to be capable and daring in unraveling it. They learn to seek the true meaning of things: to distinguish between the true and the merely seemingly true, to verify for themselves what is stable in that very unstable compound that often passes for knowledge. These are deeply personal, private goods, but they are also public goods. They are the qualities which every society needs in its citizens. That is even more the case in our European societies since our culture believes that fair and open societies, which can resolve legitimate competition between individuals and groups and harmonise legitimate differences, are only maintained by participatory democracy. It is universities that produce these citizens, or at least enough of them to leaven and lead society generation by generation.

Moreover, and once again, many of the qualities prized by government - entrepreneurship, managerial capacity, leadership, vision, teamwork, adaptability and the effective application of specific technical skills-are not primary features, but are derived from the more fundamental qualities explored in the previous paragraph. It is these qualities that policy and university management should seek to reinvigorate. The more recently advocated functions of universities are only part of a wider project which contains their essence. That capability which leads to economically significant outcomes is derivative from a deeper creativity. It has been misguidedly made to stand as a proxy for useful knowledge; but universities should read their function more widely and more intelligently.

But should we focus more of our efforts, more status, more student funding in teaching the scientific and technological disciplines that are believed to be engines of the knowledge economy, and even here to focus more on immediate applicability? We do not recognise a rational basis for a university's spectrum of taught disciplines or programmes of study other than those of student demand, the progress and potential of specific areas of study, which naturally wax and wane with the tempo of discovery, the demand for knowledge in the public domain and the prospects of employment. There is virtue in leaving students free to choose their studies without excessive direction towards subjects which will supposedly bring them or society the greatest material benefit. Studies that speak to a student's enthusiasms are more likely to stimulate the capacities of paragraph 29 above than unengaged, dutiful pursuit of a prescribed discipline. Our understanding of ourselves and of nature, and our exploitation of that understanding, remain the means whereby societies are able to progress, economically, socially and culturally. If there is a current malaise in Europe, it is likely to be as much social and cultural as economic. Understanding our past, understanding the cosmos around us, understanding our social relations, our cognition and our material selves are all parts of a nexus that is needed in a healthy and aware society, and one that is reflected in the diverse contemporary demands for literature, television and for leisure. Moreover, the processes of innovation that lead to economic development depend in practice on inspiration from this whole range of understanding, and not exclusively or particularly on a restricted part of it.

Globalisation has increased the pressure for public and private goods to be marketed and sold as commodities. It has been argued that students should be regarded as customers, with the university as service provider, a view that many university managers have accepted, either implicitly or explicitly. This redefinition assumes a direct relationship between the acquisition of specific technical skills and their deployment in specific roles in the contemporary economy. Again, it reflects expectation of an "in-out" relationship between the current demand for skills and university education. It assumes that the skills that society and the economy need are simply ones of technical specialisation, which we reject for the reasons argued above. It assumes a quasi-contractual relationship between the customer and provider, analogous to the skills one might pay to acquire in learning to drive a car. It subverts the open-ended, often transformative relationship between academics and their students that disturbs complacency and fits graduates to confront and deal with the challenges of complexity and change. The censorship exerted by current market need over what is difficult or innovative, or intellectually or aesthetically demanding can be such as to undermine the university's role 
to provide for the future.

We are aware that statements about the deeper, personal values of education can easily be traduced as sentimental attachment to an ivory tower, detached from a world of employment and the insistent utilitarian demands from a variety of stakeholders. We retort that such values are themselves utilitarian. They form a bedrock that enables the practical skills needed by society to be most intelligently deployed: those of doctors, engineers, nurses, scientists, teachers, accountants, lawyers, ministers, businessmen, social scientists, and those who will promote and perform the creative arts. The combination of deep, personal understanding and technical skill is a powerful alchemy that sustains a creative and innovative society. All universities, and their stakeholders, should be committed to its support. The annual flux of skilled graduates armed with these capacities continually refreshes society's technical excellence and its economic, social and cultural vitality, and are crucial to its capability to take bold, imaginative and principled action in the face of an uncertain future, rather than cowering in fear of it.

Neither should these values be thought of as exclusive to comprehensive research-intensive universities. The diverse institutions that now make up the University sector in Europe and beyond, which reflect both the welcome explosion in higher education for a greater proportion of the population and an increasing diversity of demand, all need to respond to these imperatives, whether they are classical researchintensive universities or universities that give priority to vocational, technical education. The point is to direct a student's attention to that which, at first, exceeds their grasp, but whose compelling fascination draws them after it. Watering down condescends to the unknown capabilities within ourselves. It condescends towards those judged, a priori, to be incapable of better things.

\subsection{Research}

Successful research, whether in the sciences, humanities or social sciences, depends upon a culture and individual attitudes that value curiosity, scepticism, serendipity, creativity and genius. They are values that are crucial to the university educational process at its most profound, and are most readily acquired in an environment of free-ranging speculation and research that is permeated by them. Their transfer into society by graduates who embody them is an essential contribution to an innovative culture and a spirit of informed civic responsibility.

Not only does its research create the frame for a university's educational role, but universities have also proved to be highly cost effective settings for basic research in particular. The reasons may lie in their non-hierarchical nature, the pervasive presence of the irreverent young, whose minds are not so full of the means of refutation that original ideas are denied entry, and the highly competitive nature of most funding for university research, in contrast to specialist research institutes, where the peace and quiet to focus on a mission, undistracted by teaching or other responsibilities, and with relatively assured funding, may be a questionable blessing [10]. By the same token, the excitable and dynamic nature of universities suits them much less well to the pursuit of longterm, strategic research objectives. This university inclination towards basic research, which seeks to explore the fundamentals of phenomena, also chimes well with their educational role, in stimulating the flexible modes of thought and creativity that are adaptable to a wide range of circumstances, and the deeply personal ownership of the basis for lifelong learning.

Universities, particularly comprehensive universities, are unique amongst human institutions in the range of knowledge they encompass. As a consequence, they have the potential rapidly to restructure and recombine their skills in novel ways to address both the many trans-disciplinary issues that are becoming increasingly important, and also to explore new, unexpected avenues of understanding. As the pace of unanticipated discovery and the urgency of demand increase, this capacity is increasingly vital, although universities have not exploited it as decisively as they should. Although much has been made of the need to develop and maintain critical mass in research, the critical diversity required to confront challenges as they arise or to create novel combinations of researchers to address evolving transdisciplinary demands is often more important. And electronic networks are no substitute for diverse and dynamic communities of place.

\subsection{Innovation}

We referred earlier to the stress currently laid on the role of universities as engines of innovation and economic development, and the drive to shift university behaviour in order to give prominence or priority to these issues. The crucial question is whether and to what extent this is true and appropriate. By implication, the European Commission believes that it is, given the equality of treatment afforded to education, research and innovation in their so-called "knowledge triangle" in its recent communication, and the way in which this is to be embedded in the European Institute of Innovation and Technology (EIT) as a putative exemplar of a world-class university for the modern world. We have no doubt that universities have a fundamental contribution to make to the innovation process, but it is important to understand what that contribution is, and not to assume, as many increasingly do, that universities are direct drivers of innovation, and that this could be their primary rationale.

Universities can and do contribute to the innovation process, but not as its drivers. Innovation is dominantly a process of business engagement with markets, in which universities can only play a minor active role. They do however 
contribute to the fertility of the environment that innovation needs if it is to flourish. University commercialization activities themselves, the creation of spin-out and start-up companies and licensing of intellectual property, do not, even in the USA, where university commercialisation is best developed, directly contribute significantly to GNP. These activities have a different role. They help to create an environment sympathetic to and supportive of innovation, and particularly where they are associated with internationally competitive research and excellent graduates, they create a hubbub of creativity that attracts research intensive companies and investment into a region, and help catalyse innovation in indigenous businesses. The bedrock for this potential remains however the university's commitment to education in the deepest sense, and its exploration at and beyond the limits of human understanding. A recent study of the role of higher education in meeting international business demands [11] concludes that it is "the quality of staff at all levels that is the most important determinant of business competitiveness". To which we would retort that the individual qualities embodied in university graduates, developed through the classical educational processes summarised in paragraph 29 , and leavened by appropriate technical skills, are crucial contributions from universities.

There is much debate about "innovation systems"; how they should be structured and the role of universities in them. The notion of a single, durable and generically applicable innovation system is a seductive concept for policy makers, but misconceived. A recent LERU report [12] gave examples of the great diversity of ways in which universities contribute to innovation processes, which vary according to the nature of the regional economy, the business sector involved and the nature of the university. Indeed it is clear that multiple innovation systems operate concurrently in the same region and that the mosaic of innovation changes through time. Innovation systems might best be defined as an "ecology" [13], in which interactions between different actors produce emergent behaviour that is highly adaptive to circumstance and opportunity.

If this is a good description of reality, it warns against generic governmental or European Commission interventions that take a prescriptive view of innovation processes or structures. A key principle is that it is autonomy of action by an institution that is aware of regional priorities that gives an institution the greatest potential to contribute, not only to market innovation, but also to innovation in cultural and social spheres. The key processes are those that stimulate interaction. It is a matter of concern that the principle of developing enabling processes that can support a wide variety of activities is often not recognised by funders of research at national and European levels, who frequently propose to reinvent and prescribe knowledge transfer structures at levels far removed from the research base. This risks increasing the constraints on universities' efforts to use intellectual property and capability creatively, and, at worst, stopping successful initiatives in their tracks [14].

It is erroneous to think of innovation, as some of these interventions implicitly do, as a supply-driven process, fuelled by inventions, often created in universities, and particularly in science and technology. Although few would admit it, this can be the only rationale for some governmental policies of recent years. In practise, although attention must be given to the quality of supply of excellent education, excellent research and responsiveness to business needs, this of itself is not enough. Where demand is weak, excellent supply has rarely been sufficient to stimulate it. Governmental intervention has often been a powerful stimulus for demand, with government use of public procurement of research products from companies as a particularly potent device for stimulating the growth of knowledge-intensive companies and increasing private investment in R\&D [14]. It is also the case that as the service sector becomes predominant in developed economies, knowledge-intensive growth depends on a much wider range of inspiration than just science and technology, and in which the arts and humanities are playing an increasing role [15].

It is a common myth that the primary deficit in innovation is failure to exploit research inventions, and to overcome this deficit, that universities should be more pro-active agents of innovation. The university role in innovation is in developing human capital, at bachelors, masters and doctoral levels; in contributing to the intellectual, social and cultural resources of a region in ways that encourage inward investment of knowledge intensive business; in helping to stimulate entrepreneurial activity; and in collaborating with business to create mechanisms of interaction.

\subsection{Public engagement}

Academics have long contributed freely their specialist knowledge or distinctive perspectives to public bodies, and to a broader public through lectures, debate, discussion or performance, and as "public intellectuals", who take on a public role to stimulate debate or social activism. Much of this engagement is negotiated with and by individual academics and their students, often without the formal consent or even knowledge of their universities. It is part of the "halo" effect of a university, and depends entirely on the presumption that autonomous academics have the freedom, and the duty, to promote learning and understanding. Though a "cottage industry", its aggregate contribution to civic society can be very great.

It is timely that this aspect of university capacity should be better cherished and rewarded by the universities themselves and recognised and supported by government. The increasing priority for "evidencebased" public policies depends on access to a wide range of specialists, many based in universities, and the willingness of academics to be called upon for advice and involvement in the policy process. Equally there are many major current issues, such as climate 
change, energy, food security, and genetic manipulation, that lie both at the margin of scientific understanding and in the domain of ethical contention, such that deliberative public engagement with the issues and uncertainties associated with them is required if effective and publicly acceptable policies are to be introduced. Academics' reputations for independence and their credibility make them ideal interlocutors in such debates whilst their universities provide an ideal, neutral space for engagement. These are challenges and opportunities to which the modern university must respond.

However, in an age that reveres management, metrics and regulation, the perception that such engagement is an important part of the role of the university, its academics and its students, naturally leads government and funding bodies to encourage its corporate management. The temptation is to assume that such activities need to be measured and incentivised, leading to a duller, more routinely managed effort, which is increasingly seen as an imposition justifying payment or contract rather than a natural expression of the university ethos and of the academic vocation. The challenge is in part for university managers, to create, with a light touch, an enabling environment that supports and encourages such activity, exploiting the university's greatest strength, its diversity of inspiration, rather than stifling it by overmanagement or inappropriate metrics. In part the challenge is for government and other bodies to express the need and to fashion the processes through which such inputs to public policy and engagement can be made.

\subsection{International engagement}

Academic scholars have maintained networks of international links since the early days of universities, long before the phenomenon of globalisation ushered in by the recent communications revolution. That revolution has destroyed geographical barriers to communication and interaction, such that we now live in a novel world of virtual proximity, global perception and awareness. Some take an optimistic view of these developments, that they "will increase understanding, foster tolerance, and ultimately promote worldwide peace" [16]. Others are more pessimistic. They see a world in which we are no longer cocooned in ignorance of the elsewhere, but borne in on by every drama, every twist of fortune as it happens, wherever it happens, and with social attitudes and political processes that are illadapted to cope with these changes. But irrespective of the outcome, the opportunity for universities to play an independent, mediating role in this changing world is clear. Internationally, they are located in different cultural milieus, but they share a common ethos that permits them to collaborate across cultural divides and to deepen in their students a sympathy for and understanding of the diversity of cultural assumptions and the complexities of the modern world. Over the last decade, universities have begun to develop international corporate links and networks that are increasingly used in structured ways to intensify dialogue, to articulate educational collaborations and to undertake joint research on major global problems. A convergent trend, that of increasing student mobility, should be seized on by them as the basis for the common task of educating the rising generation as global citizens, rather than merely as contributors to a university's finances or to the national workforce. These changes in behaviour, the rational and humane values that universities increasingly share, and the democratising force that they represent, also make it timely for them to find a common voice in intervening in international debate about global issues.

\section{The importance of the humanities and social sciences}

The arguments presented above are generic arguments, applicable to the whole spectrum of university disciplines. However, we wish to single out and underline the role of the humanities and social sciences, as government policies for universities, particularly in research, too frequently concentrate on science, technology and medicine, with a perfunctory nod towards the humanities and social sciences that implicitly undervalues their importance for society.

The humanities are concerned with what it means to be human: the stories, the ideas, the words that help us make sense of our lives and the world we live in; how we have created it, and are created by it. They give voice to feeling and artistic shape to experience, exploring issues of morality and value. The social sciences attempt to deduce, through scientific observation, the processes that govern the behaviour of individuals and groups. They are crucial to the creation of effective social policy.

There is an implicit notion that the understanding they confer is less important than that loosely termed "science", although natural scientists themselves rarely take that view. Research in the humanities and social sciences is concerned with issues that are essential to stability, good order, creativity and inspiration in society. In these disciplines are gathered the thinking, learning, and explanation of what binds and what separates human beings. They seek not only to understand and make accessible that extraordinary intensity and complexity of beauty by which humans specify themselves in the merging of thought, emotion and expression - a high enough mission by any standard. More important for our purpose, they provide understanding of why and how we express differently our common characteristics of being, as well as how we differ as individuals, groups and cultures. History - and none more so than recent and contemporary history-demonstrates how supremely important the dissemination of that understanding is to stable and healthy societies. Globalisation, especially in its effects of instantly accessible worldwide information, and increasingly mobile populations, has created political complexity 
by bringing once distant cultural assumptions into close proximity, and makes this an ever more pressing necessity. It would be absurdly naive to argue that an understanding society (another form of "knowledge society") would be devoid of divisive competition and destructive conflict. At the same time, though, ignorance is the surest route to panic, hatred, and devastation.

Research in the arts, humanities and social sciences is a core resource and stimulus for cultural performance, exhibition and maintenance of the historic environment, and is increasingly embedded in the norms of popular culture. It promotes historical understanding of our own and other cultures, religions and societies. It fosters public debate and engagement with the complexities of modern life, especially those which involve conflicting moralities, traditions and beliefs. Through its humane values, it provides crucial support for civic virtues and open, accessible government, on which civilised society depends. Its societal and humane focus addresses major current social, cultural, ethical and economic challenges, including the impact of scientific and medical advances, the management of international relations, development and security, and the effects of globalisation and migration. It contributes decisively to today's recognition that modern society depends on the whole range and interconnectedness of knowledge rather than on a few academic disciplines. It makes an increasingly effective practical contribution, together with other disciplines, to the creation of public policy.

The acknowledgement that moral, social and political progress have not kept pace with mastery of the physical world shows the need for more intensified research, fresh insights, vigorous criticism and inventiveness in the humanities and social sciences. Many major contemporary issues, the introduction of novel and disruptive technologies, policies for health, education and penal reform, the consequences of climate change and the development of new energy systems require engagement across the whole disciplinary spectrum if they are to be rationally addressed.

\section{The challenge for university governance}

We wrote at the beginning of this essay of "the openness to contradiction that is part of the genius of the university". One of those contradictions derives from the relative freedom and autonomy of academics, and the lack of inhibition of its students; which are the source both of the university's greatest strength and its greatest weakness. On the one hand it generates a hubbub of creativity and entrepreneurial initiatives that stimulate diverse and sometimes towering intellectual achievement. On the other, it can be the source of profound resistance to managed change or the orchestration of joint efforts in response to changing societal needs. A central dilemma for university governance is therefore how to retain the sense of ownership of the university enterprise by its members, which creates the setting for their creativity to range freely, whilst implementing the structural changes that are inevitably needed from time to time if a university is to remain a creative force for future generations.

Managing such a university is not like managing industrial production in response to market demand. There is a core of the university operation that requires efficient topdown management, such as the framework for teaching, the structures of research support, technology transfer and professional services. But the crucial attribute, for both students and academics, is a culture of individual freedom, creativity and serendipity. It provides the frame for new insights and understanding; gives free rein to the enthusiasms and commitment that lead to public engagement; and for the space to create new enterprises that as they mature can be absorbed into the formal operation of the university, and so change its shape and direction. A current danger in many countries stems from the financial benefits that come to a university through research funding mechanisms. These can be such powerful drivers of behaviour and corporate motivation that top-down mechanisms are driving some institutions close to becoming strongly managed research institutes, squeezing out diversity of function and undermining teaching and learning.

Political boldness is also required. The freedom to enquire, to debate, to criticise and to speak truth to power, whether it be the power of government, of those that fund the university, or those who manage it, is central to the vitality of the university and its utility to society. It is crucial that rectors and university governing boards understand this essential source of institutional strength, that they are steadfast in its support, strong in its defence and are not seduced by the fallacy of managerial primacy: that things that make management difficult necessarily need to be removed or reformed. An easily governed university is no university at all.

\section{Academic freedom and trust}

Such freedom however poses a dilemma for government. For bodies that are largely funded from the public purse, universities and their staff have a unique freedom from governmental direction and control. But in an era where there is said to be a deepening crisis of trust and a culture of suspicion about public bodies and professionals, the demands for accountability in exchange for this freedom have grown. Although there has been widespread recognition of the value of university autonomy in permitting institutions to act decisively and flexibly in response to need or opportunity, and where state control is recognised as having been a barrier to development, freedom is necessarily accompanied by calls for greater accountability. However, accountability can often be control by another name. Increasingly bureaucratic mechanisms of accountability have been established 
to verify that the trust implied in freedom from control is justified. Detailed regulations, memoranda, instructions, guidance, and lists of "best practice" flood into institutions, too frequently focussing on processes rather than outcomes. Even then, such mechanisms rarely penetrate sufficiently deeply into the processes they are supposed to verify to achieve their aim. Quality assurance does not measure the quality of education, merely some of the second- order issues associated with education. Their principal result is to impose unproductive bureaucratic burdens. It is vital to understand that such mechanisms can ultimately undermine the outcomes that are a university's principal benefit to society. The challenge to universities, government and society is to articulate a compact that recognises the value of autonomy and freedom and supports them, but is able to assess the value and benefit without oppressive mechanisms that undermine a university's potential.

One of the dilemmas facing governments where they are the major funder of universities, is to find an appropriate basis for funding: one that will enable them to be bold and creative in using their capacities to address the diversity of functions alluded to in this essay. Whilst universities should be funded for how well they do the things that make them what they are, it is too easy to develop one or two lines of funding, driven by metrics that stand proxy for deeper, elusive qualities, that so drive university behaviour that they pour excessive efforts into the satisfaction of the metric rather than the properties metrics attempt to measure. Such metrics can also have the perverse consequence of driving out much of the creative diversity of behaviour that is one of the university's great strengths.

\section{Conclusions}

It is our contention that slipshod thinking about the roles that universities can play in society is leading to demands that they cannot satisfy, whilst obscuring their most important contributions to society, and, in the process, undermining their potential. It is wrong, in our view, to expect (to use language from the beginning of this paper) that universities will be dynamos of growth and huge generators of wealth, leading to economic prosperity and enhanced quality of life on anything like the scale that is implicit in such language. In a European context, where governments are principal funders of universities, the assumption is that they are a lever which, when pulled, will gush forth the tangible effects of economic prosperity into which public money has been transformed. In reality, universities can only be one part of the process of producing a successful knowledge economy. The oft-quoted example of Silicon Valley and Stanford University is far more subtle and complex than a simple reading allows. It is a compound of capitalist enterprise, technical and legal services, skilled labour, a broad range of social provision in the public domain, local and state government policy, the appetites of an historically entrepreneurial culture, and maybe even climate. The exact part of universities in all that is not easy to measure. This is akin to saying that humans would not exist without sperm and egg. Of course not; but they are not what creates that wonderful diversity of individualities amongst which each one of us has their own place. To confine universities to such a mechanical place in the progress of society is to diminish them; it invites doomed attempts to measure intangible effects by unyielding metrics; it offers only eventual disillusion.

Universities deal with the universality of knowledge; they are concerned with human beings in all their manifestations-biological, mental, emotional, objective and subjective-and their social, cultural and economic organisations and interactions with each other; they are concerned with the physical world within which human beings find themselves. They seek to under- stand that which we do not understand; they seek to explain complexity; they seek to discover that which is hidden from us. They seek to establish what is common to all of us and what distinguishes us each from another or each group from another. These things are common to the whole of university endeavour whatever the discipline. They are not "academic" in the pejorative sense of the word, but are of profound, practical utility. They are the foundation upon which the university enterprise rests and upon which its significance for society is built.

There are two important points to derive from these propositions. The first is that it is the totality of the university enterprise that is important. One cannot simply separate one element and say that is what we want and that is what we will pay for. Human society is not separable in the way that governments would necessarily wish to decompose it for the purpose of discrete policy actions. It is a complex interacting whole, which needs to be understood as a whole. No one discipline suffices to seize the whole-whether the whole individual or the whole social construct. Of course, public policy will place a premium on this or that aspect at different times, but it cannot simply set about neglecting the rest on the purely temporary and therefore relative grounds of a present concern. Indeed, universities are the only place in society where that totality of ourselves and our world is brought together. It is universities in their diversity of preoccupations that are the strongest providers of rational explanation and meaning that societies need.

Universities are not just supermarkets for a variety of public and private goods that are currently in demand, and whose value is defined by their perceived aggregate financial value. We assert that they have a deeper, fundamental role that permits them to adapt and respond to the changing values and needs of successive generations, and from which the outputs cherished by governments are but secondary derivatives. To define the university enterprise by these specific outputs, and to fund it only through metrics that 
measure them, is to misunderstand the nature of the enterprise and its potential to deliver social benefit. These issues of function and purpose are important, and need to be explicit. They must be part of the frame for the animated debate taking place in Europe that generates headlines such as "creating an innovative Europe"[17], "delivering on the modernisation agenda for universities"[18], and "the future of European universities: renaissance or decay?"[19].

The second point is that the instinct to understand, to find meaning, to map oneself and one's actions and the world, is essentially human. In our view, this is one of the principal definitions of humanity, even if one were to reduce it simply to primordial angst. Knowledge is a human attribute, quite distinct from, say, the tool-making skills of the New Caledonian crow or the communication skills of the chimpanzee. Therefore, those parts of the university and its research which deal with the human being as an individual or as a collectivity (that is, the humanities and the social sciences) are as important as science and technology and are as central to the well-being of society.

1 Newman J H. The Idea of the University. Notre Dame: Notre Dame University Press, 1852

2 Humboldt W von. Über die innere und äussere Organisation der höheren wissenschaftlichen Anstalten in Berlin. In: Leitzmann A, ed. Wilhelm von Humboldts Gesammelte Schrifte. Gesammelte Schriften zur Literatur, Band X. Berlin, 1903. 35

3 European Commission. Delivering on the Modernisation Agenda for Universities: Education, Research and Innovation. COM 208, 2006

4 European Commission. Facing the Challenge: The Lisbon Strategy for Growth and Employment. Report from the High Level Group Chaired by Wim Kok, 2004

5 European Commission. The European Research Area: New Perspectives. COM 161, 2007

6 European Commission. Globalisation of R\&D: Linking Better the European Economy to Foreign Sources of Knowledge and Making EU a More Attractive Place for R\&D Investment. Report from the Expert Group on Knowledge for Growth, D.Foray (rapporteur), 2007

7 Batterham R. The Chance to Change. Canberra: Australian Department of Industry, Science and Resources, 2000

8 Faust D. The Boston Globe. Boston, Massachusetts, October 12, 2007

9 Fukuyama F. The End of History and the Last Man. London: Penguin, 1992

10 May R M. The scientific wealth of nations. Science, 1997, 793-796

11 Richard B. International Competitiveness Competitiveness \& the Role of Universities. London. Council for Industry and High Education, 2007

12 Boulton G S. Universities and Innovation: The Challenge for Europe. Leuven: League of European Research Universities, 2006

13 David P A, Metcalfe S. Universities and Public Research Organisations in the European Research Area. Report from the Expert Group on Knowledge for Growth, 2007

14 Boulton G S. The Future of the European Research Area. Leuven: League of European Resgearch Universities, 2007

15 Richard B. International Competitiveness Competitiveness \& the Role of Universities. London: Council for Industry and High Education, 2007

16 Cairncross F. Death of Distance. New York: Texere, 2001

17 European Commission. Creating an Innovative Europe. Report of the Independent Expert Group Chaired by Esko Aho. 2006

18 European Commission. Delivering on the Modernization Agenda for Universities: Education, Research and Innovation. Brussels. COM 208, 2006

19 Lambert R, Butler N. The Future of European Universities: Renaissance or Decay? London: Centre for European Reform, 2006

Open Access This article is distributed under the terms of the Creative Commons Attribution License which permits any use, distribution, and reproduction in any medium, provided the original author(s) and source are credited. 